\title{
La industria automotriz colombiana y sus retos competitivos frente al entorno económico*
}

\author{
The Colombian automobile industry and its competitive \\ challenges considering the economic environment
}

\section{A indústria automotiva e seus desafios competitivos perante 0 ambiente econômico}

\author{
Roberto Carlos Torres-Castellar \\ Ph.D (c) - Candidato a Doctor en Ciencias Económicas, MBA - Magister en Administración,Especialista en Gerencia del Talento Humano, \\ Economista. Fundación Tecnológica Antonio de Arévalo - Tecnar. Cartagena, Colombia. \\ Coordinador de investigación de la Facultad de Ciencias Económicas. \\ roberto.torres@tecnar.edu.co
}

\author{
Jairo Argemiro Mendoza-Álvarez \\ Magíster en Administración, Especialista en Gerencia de Mercadeo, Ingeniero Industrial. \\ Fundación Tecnológica Antonio de Arévalo - Tecnar. Cartagena, Colombia. Decano de la Facultad de Ciencias Económicas. \\ jairo.mendoza@tecnar.edu.co
}

\section{Resumen}

Se presenta la situación de la industria colombiana automotriz con respecto a su entorno macroeconómico para el año 2014, y los posibles cursos estratégicos de acción. Desde que en los años 2011 y 2012 se pusieron en marcha los tratados de libre comercio en Colombia, el panorama de esta industria sufrió un duro golpe por la inclusión de nuevas marcas y nuevas tecnologías al territorio nacional, capaces de cumplir con las expectativas de los consumidores muy por encima de las características ofrecidas por la producción nacional. Esta industria debe encontrar la manera de optimizar sus costos con el fin de ofrecer precios competitivos con la industria automotriz extranjera, y mucho más cuando ya se tiene un gran segmento de la población pagando precios más bajos por los vehículos importados, muy por debajo de los precios locales. La innovación juega un papel importante, el posible rol de apoyo del Estado consistiría en financiar la amplificación de la infraestructura de las ensambladoras, brindar apoyo al diseño e innovación en toda la cadena productiva de la industria automotriz nacional, con el propósito de reducir los

* Cómo citar: Torres-Castellar, R. C., Mendoza-Álvarez, J. A. (2017). La industria automotriz colombiana y sus retos competitivos frente al entorno económico. Revista Libre Empresa, 14(1), 133-146 http://dx.doi.org/10.18041/libemp.2017.v14n1.27106 
costos de fabricación y hacer que los precios nacionales compitan directamente con los internacionales.

\section{Palabras clave}

Industria automotriz colombiana, organización industrial y macroeconomía, política industrial.

\section{Abstract}

This paper discusses the situation of the automobile industry in Colombia with respect to its macroeconomic environment in 2004 and potential strategic courses of action. Since the free trade agreements became effective in Colombia in 2011 and 2012, the landscape of the automobile industry suffered a harsh blow due to the introduction of new brands and technologies that were able to meet the consumer's expectations with characteristics that exceeded those of national products by far. This industry has to find a way to optimize costs in order to offer prices that can compete against those of the foreign automobile industry, especially considering that there is already a large segment of the population that is paying lower prices for imported vehicles - far below local prices. Innovation plays a major role. The State could play a role to support this industry by funding the expansion of the infrastructure of assembly plants, providing assistance with the design and innovation throughout the production chain in the domestic automobile industry aiming at reducing manufacturing costs, and making national prices compete against international prices directly.

\section{Keywords}

Colombian automobile industry, industrial organization and macroeconomy, industrial policy.

\section{Resumo}

É apresentada a situação da indústria automotiva colombiana com respeito a seu ambiente macroeconômico para o ano 2014 e os possíveis cursos de ação estratégicos. Desde que no ano de 2011 e 2012 foram iniciados acordos de comércio livre na Colômbia, as perspetivas para esta indústria sofreram um duro golpe pela inclusão de novas marcas e novas tecnologias em território nacional, capazes de atender às expectativas dos consumidores, muito acima das funcionalidades oferecidas pela produção nacional. Esta indústria deve encontrar formas de otimizar seus custos a fim de oferecer preços competitivos com a indústria automotiva estrangeira, e muito mais quando já existe um grande segmento da população pagando preços mais baixos pelos veículos importados, muito inferiores aos preços locais. A inovação desempenha um papel importante, o possível papel do apoio do estado consistiria em financiar a ampliação da infraestrutura das empresas de montagem, apoiar a concepção e a inovação em toda a cadeia de produção da indústria automotiva nacional, com o objetivo de reduzir os custos de fabricação e fazer com que os preços domésticos possam competir diretamente com os internacionais. 


\section{Palavras chave}

Indústria automotiva colombiana, organização industrial e macroeconomia, política industrial.

\section{Introducción}

Desde la apertura económica y la firma de acuerdos comerciales entre Colombia y los países con los cuales se firmaron tratados de libre comercio, una de las industrias que ha sufrido efectos secundarios de forma negativa ha sido la automotriz y las autopartes. Se presenta la situación de la industria automotriz colombiana en el año 2014, los posibles cursos estratégicos de acción, y se explica cómo el Estado interviene a través del establecimiento de políticas de fijación de precios, medidas arancelarias, estrategias de impulso a la economía de la industria seleccionada para su estudio, en este caso, las cuales han venido presentando una situación poco alentadora desde que se colocaron en vigencia los tratados de libre comercio con México, Corea del Sur, India, Japón, Estados Unidos, entre otros; países que son potencias mundiales en la fabricación de vehículos y autopartes.

La entrada al país de nuevas marcas y prototipos ha creado un caos entre los fabricantes de autos nacionales, e inclusive ha causado el cierre de una de las más importantes ensambladoras de la marca Mazda, la cual se trasladó a México debido a que en Colombia no trabajaba a su máxima capacidad, solo un 30\% era utilizado, llegando a la conclusión de que es más económico adquirir los vehículos Mazda importándolos desde México que producirlos en el territorio nacional.

El gobierno colombiano tomó medidas al respecto otorgando líneas de crédito para evitar que las demás ensambladoras corran la misma suerte, pero sus esfuerzos fueron en vano. La tendencia a la baja se mantiene, el Estado no se pronuncia al respecto y los efectos parecen cobrar mucho más fuerzas en la medida en que se han ido poniendo en marcha los acuerdos internacionales con lo que a la industria nacional le toca replantear sus estrategias y encontrar la mejor forma de, por lo menos, contrarrestar este fenómeno, en el cual ya los consumidores hacen parte activamente solicitando al mercado vehículos que sean asequibles al presupuesto de cada uno de ellos.

Por otro lado, se pretende explicar cómo estas intervenciones realizadas por el Estado se ven reflejadas en el comportamiento de la demanda y de la oferta desde el punto de vista de los excedentes tanto del consumidor, como del productor. Así como los efectos en las elasticidades con y sin la intervención del Estado en la industria.

En el caso colombiano, y en especial en la industria automotriz, estos efectos no han surtido resultado alguno, mostrando así la ineficiencia del gobierno en el planteamiento estratégico de medidas que impulsen nuevamente este sector para que pueda sobrellevar los impactos que han traído consigo los TLC con los países con que Colombia mantiene relaciones comerciales. 


\section{Caracterización de la industria automotriz colombiana}

De acuerdo con la ANDI (2014) en Colombia operan las siguientes ensambladoras:

1. Compañía Colombiana Automotriz (marca Mazda).

2. General Motors Colmotores (marcas Isuzu, Volvo y Cheverolet).

3. Sofasa (marca Renault).

4. Hino Motors Manufacturing S.A (marca Hino - grupo Toyota).

5. Carrocerías Non Plus Ultra (marca propia, CKD Wolkswagen).

6. Compañía de Autoensamble Nissan (marca Nissan).

7. Navistrans S.A. Agrale.

8. Daimler.

En Colombia, la industria automotriz está determinada por dos operaciones fundamentales: ensamble y autopartes. Más allá de la transformación de materias primas, la industria automotriz se caracteriza principalmente por el ensamble de vehículos desarrollado en tres etapas esenciales: armado, montaje y pintura, que son el resultado de la adquisición de otros procesos de producción. Podemos clasificar esta industria como un oligopolio debido a que las cuatro primeras empresas concentran el 99\% de la producción, en términos de unidades.

La industria automotriz representa un $4 \%$ del Producto Interno Bruto (PIB) industrial, generando alrededor de 25.000 empleos directos entre la industria terminal y los proveedores nacionales de autopartes, y cerca de 100.000 empleos indirectos a causa de la red de comercialización, representada por talentos humanos de alta calidad y salarios que sobrepasan el promedio en comparación con otros sectores (Revista Sectorial, 2014).

En Colombia se presentó un notable decrecimiento en el consumo de bienes durables desde el año 2012. Este fenómeno fue derivado de la normalización del ciclo de crecimiento de este tipo de bienes, que para el año 2010 había presentado tendencias al alza debido a que las tasas de interés que se encontraban vigentes en el mercado, habían bajado (Corficolombiana, 2012).

Al finalizar el 2013, la venta de vehículos se situó en los COP 11,3 billones corrientes (1,6\% del Producto Interno Bruto total), cifra que ha permanecido constante desde el año 2011. Sin embargo, su participación en el PIB total ha venido decayendo desde 1,8\% en 2011, y aún más si se compara este valor con el alcanzado en el año 2007, el cual se encontraba situado en un 2,5\% del PIB (BBVA, 2013).

Con respecto a las ventas, en el año 2013 se vendieron cerca de 293.846 vehículos, mientras que en los años 2011 y 2012, las ventas alcanzaron los 325 y 316 mil vehículos, respectivamente. El $80 \%$ de los vehículos matriculados en el país se ubicaron para uso privado, mientras que sólo un 18,7\% se destinó al servicio público (BBVA, 2013, p. 3). Por otra parte, la importación de vehículos, dada en gran medida por los tratados de libre comercio con México, Estados Unidos y China, ha causado un descenso significativo en la participación de esta industria en el consumo nacional de vehículos, pasando del $48 \%$ al $32 \%$. 
Mientras tanto, el mercado de vehículos usados muestra un panorama similar al de los vehículos nuevos. En el año 2011 se comercializaron 577.430 vehículos, en el 2012 este valor disminuyó a 519.887 y en 2013 se posicionó alrededor de 490.000 unidades. La disminución en el precio de los vehículos nuevos y las bajas tasas de interés son razones económicas de fondo para un comportamiento sustitutivo de los usados por los nuevos, además de la menor demanda generalizada por bienes durables que también afectó a los carros nuevos (BBVA, 2013, p. 3). (Ver Tabla 1 ).

\section{Tabla 1.}

Distribución de las ventas de vehículos por tipo y por sector destino, año 2013.

\begin{tabular}{|c|c|c|}
\hline Tipo de vehículo & Servicio público & Servicio privado \\
\hline Automóviles & 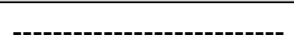 & $63 \%$ \\
\hline Utilitarios & $11 \%$ & $29 \%$ \\
\hline Pick Ups & $8 \%$ & $6 \%$ \\
\hline Camiones & $16 \%$ & 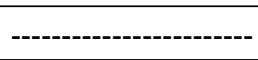 \\
\hline Camionetas & $10 \%$ & 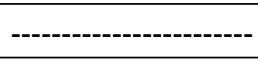 \\
\hline Taxis & $30 \%$ & -----------------------' \\
\hline
\end{tabular}

Fuente: Elaboración propia a partir de DANE (2014).

Según los informes publicados por la Dirección de Impuestos y Aduanas Nacionales (DIAN) y el Departamento Administrativo Nacional de Estadística (DANE), en el transcurso del año 2013 esta industria exportó 48.866 vehículos, mientras que en el año inmediatamente anterior, la cifra de exportación de vehículos sólo alcanzaba un total de 25.798 unidades, lo que se traduce en un incremento en las exportaciones del $89 \%$ (DANE, 2014).

En la oferta automotriz de Colombia se conserva lo notable de estas importaciones, aunque se frenó la pérdida de participación de los vehículos que fueron ensamblados internamente.

\section{Métodos}

La investigación es de tipo proyectiva. Se busca describir cuál es la situación actual de la industria automotriz colombiana, por qué se llegó a este estadio y proponer soluciones a la problemática experimentada.

Para realizar la comparación, el antes y el después de los cambios sufridos en el entorno macroeconómico, además de los efectos de la intervención del Estado, se recurre a la técnica del análisis del excedente del consumidor y del productor y del comportamiento de la elasticidad de la oferta y la demanda. 


\subsection{Excedente del consumidor}

Se entiende por excedente del consumidor la cantidad de dinero máxima que un individuo determinado, en su condición de consumidor, estaría dispuesto a pagar por un bien o la prestación de un servicio y el valor realmente pagado.

En otras palabras, este concepto basado en la ley de oferta y demanda, representa la utilidad monetaria adquirida por los consumidores, cuando pagan por un bien o por la prestación de un servicio, por debajo del precio que estarían dispuestos a pagar.

Otro concepto moderno es el que ofrece donde define el término de excedente del consumidor como la medición del grado de bienestar que obtienen los individuos en su conjunto por poder comprar un bien en el mercado, mostrando la diferencia entre la cantidad máxima que está dispuesto a pagar un consumidor por un bien y lo que realmente paga (Pindyck, R. \& Rubinfeld, 2009).

Plasmando gráficamente este concepto, el área percibida por los puntos a, b y c, hace referencia al excedente del consumidor, debido a que hay compradores que dependiendo de los factores que influyen en la demanda como calidad, exclusividad, precio, nivel de ingresos, entre otros; están dispuestos a pagar precios mucho más altos de los que ofrece el mercado, generando así para ellos un ahorro o beneficio económico. Si el precio del mercado baja, muchos más consumidores se favorecen, dado que se atiende a un nicho mucho más amplio del mercado con precios competitivos, dando como resultado un beneficio total para los consumidores. (Ver Figura 1).

Excedente del consumidor con precio $P_{1}$

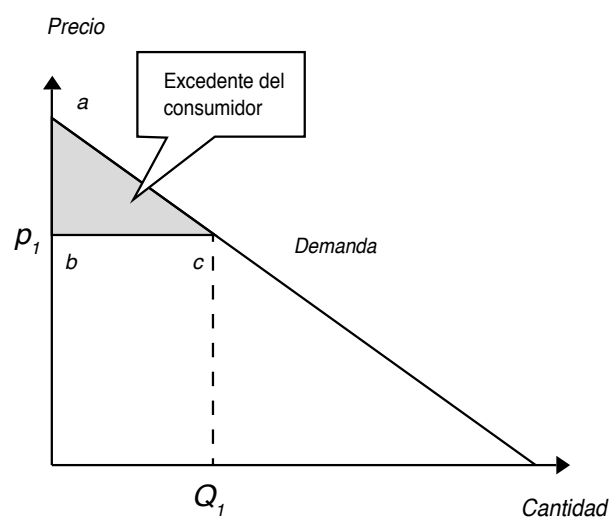

Excedente del consumidor con precio $P_{2}$ Precio

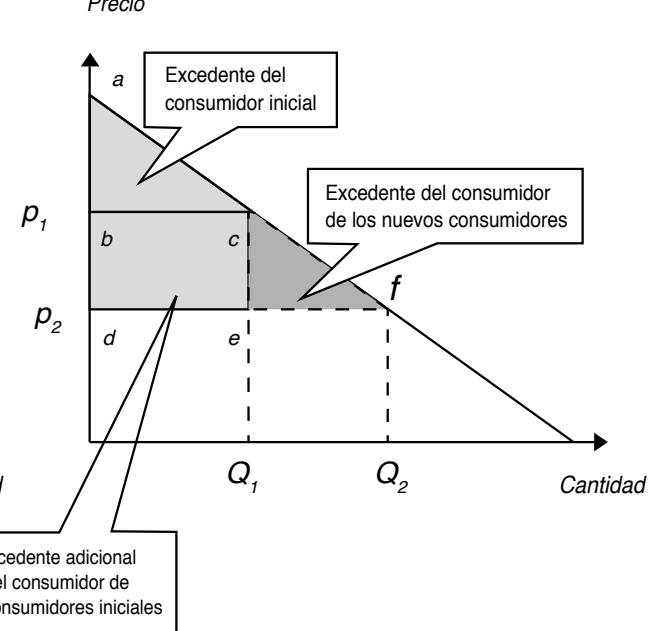

Figura 1. Comportamientos del excedente del consumidor

Fuente: Elaboración propia. 


\subsection{El excedente del productor}

El excedente del productor está definido como la suma de la diferencia entre el precio de mercado del bien y el costo marginal de producción en todas las unidades producidas (Pindyck, R. \& Rubinfeld, 2009).

En otras palabras, es el beneficio adicional que los productores obtienen por la venta de sus productos, ya que son capaces de venderlos a un precio mucho mayor del que estarían dispuestos a cobrar.

De acuerdo con lo anterior, y teniendo en cuenta la representación gráfica de este concepto, el excedente del productor está enmarcado en el área trazada por los puntos a, b y c. Del mismo modo, si los precios de los bienes o servicios aumentan, el excedente del productor aumenta, haciendo que muchas más empresas se beneficien de los nuevos precios del mercado, ya que cuentan con costos marginales más altos. (Ver Figura 2).

Excedente del productor con precio $P_{1}$

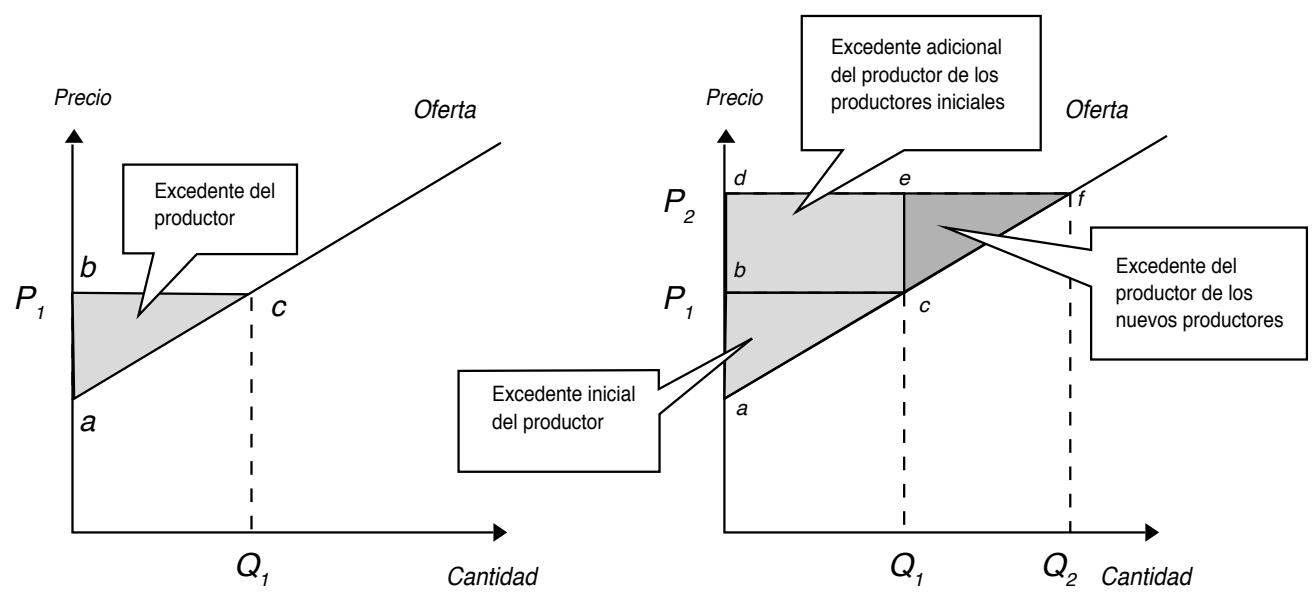

Figura 2. Comportamientos del excedente del productor Fuente: Elaboración propia.

\section{Situación de la industria automotriz y efectos de la intervención del Estado}

La muestra mensual manufacturera desarrollada por el DANE, reveló que la situación laboral en la industria automotriz sigue una tendencia a la baja. El personal ocupado presentó un decrecimiento del $16,8 \%$ en lo que corresponde a vehículos automotores y motores en el 2013, mientras que en la fabricación de partes, piezas y accesorios, se observó una disminución del 9,5\%. Escenario revelado principalmente por una reducción del 17\% de la producción vehicular en el 2013, frente al 2012. 
Los tratados de libre comercio han provocado un impacto negativo sobre la producción industrial de vehículos y autopartes. Tratados como los realizados con México y Corea del Sur han dejado al descubierto las debilidades de una nación que se enfrenta abiertamente a los mercados internacionales sin una estructura cimentada con políticas gubernamentales que impulsen el desarrollo competitivo y que se nivele con los avances en ciencia y tecnología de los países con los cuales se han rebajado las barreras al comercio.

México es el país con mayor participación en las importaciones de vehículos realizadas en el 2013 con un $27 \%$, seguida de Corea del Sur con un 21\%, China con un 11\%, Japón con un 7\%, India con un 6\% y Estados Unidos con un 6\%, entre otros (Revista Dinero, 2014).

Asimismo, el valor del dólar frente a la moneda nacional ha quebrantado la contribución de la producción nacional en los mercados nacionales, ya que desde el año 2011 se han percibido los efectos negativos provocados por la implementación del TLC con México.

Por el lado de las exportaciones, el panorama es aún más abrumador. Países como Ecuador, Venezuela, Argentina y Brasil procuran aplicar medidas internas que restringen sus importaciones, afectando directamente las exportaciones de Colombia.

Debido a estas circunstancias, la Compañía Colombiana Automotriz (CCA), cerró sus operaciones en el territorio nacional y advirtió la posibilidad para que la marca Mazda inicie una nueva etapa como una empresa exclusivamente importadora. Esta decisión trajo como consecuencia la pérdida de 500 puestos de trabajo, los cuales habían presentado una disminución notoria, ya que el año inmediatamente anterior el número de empleados alcanzaba los 1.600 .

Tan sólo el 30\% de la capacidad instalada era utilizada para la fabricación de vehículos de la marca Mazda (60 vehículos por día) y la puesta en marcha de los acuerdos económicos entre Colombia y México en materia de cero arancel, hizo poco rentables las operaciones de la CCA, debido a que resulta más costoso ensamblar un auto en Colombia que importarlo desde México.

La situación preocupante para el gobierno nacional es que la industria automotriz está lejos de alcanzar su punto de saturación y ya se están presentando inconvenientes que le han costado a esta industria una contracción económica, con repercusiones en el empleo nacional.

Como medida para contrarrestar esta realidad, el Estado colombiano pretende otorgar tarifas arancelarias preferenciales para los bienes intermedios y para todas aquellas materias primas utilizadas en el ensamblaje de vehículos y la fabricación de autopartes. Y como complemento a esta determinación, presentó el Plan de Impulso a la Productividad y el Empleo (PIPE) con un plan de financiación por 800 mil millones de pesos, el cual encierra dos líneas de financiación. 
La primera línea hace referencia a la inyección de capital de trabajo para optimizar el flujo de caja de las empresas productoras, modificando sus créditos y concediendo plazos más largos. La segunda línea hace menester en la reconversión industrial en activos fijos y financiamiento del capital de trabajo, otorgando créditos con un cupo de \$50 mil millones de pesos.

Por otra parte, la creación del Programa de Fomento para la Industria Automotriz (PROFIA), por medio del Decreto 2910 del 17 de diciembre de 2013, el cual fue expedido a través del Ministerio de Comercio, Industria y Turismo, cuyo objetivo se basa en equilibrar la importación de productos, específicamente de aquellos insumos que se emplean en las operaciones de ensamblaje y que son producidos localmente. En otras palabras, aquellas empresas que importen partes necesarias para la producción de un vehículo deberán pagar un arancel. Solo aquellas empresas que importen insumos que realmente no se fabriquen en el país quedarán exoneradas de esta medida (Mincomercio, 2013).

Lo cierto es que estas medidas tomadas por el gobierno para salvaguardar la industria automotriz se han quedado cortas, ya que la inyección de capital gestionada por el Estado colombiano por medio de Bancoldex, a través de las líneas de crédito antes mencionadas y por las políticas arancelarias para impulsar la producción nacional y frenar la importación de vehículos y autopartes ha sido insuficiente y no ha alcanzado las expectativas de los industriales de este sector, lo que ha generado el cierre de una de las más importantes ensambladoras de vehículos de Colombia y el despido masivo de trabajadores desde que empezó a decaer esta industria. Los avances en la tecnología y la investigación y desarrollo de nuevos prototipos para lanzarlos al mercado se han quedado rezagados con miras a fortalecer la industria de fabricación de vehículos y autopartes en el mercado nacional.

\subsection{El excedente del consumidor y la elasticidad de la demanda}

En el caso de la industria automotriz, teniendo en cuenta la situación actual del país en materia de comercio internacional con la apertura económica a los mercados de México, Corea del Sur, India, entre otros, y con el cierre de la CCA, las políticas gubernamentales tomadas para la protección de la industria nacional en ensamblaje de vehículos y la fabricación de autopartes, que hoy por hoy, desde que fue aprobada por el Congreso de la República, no ha tenido éxito y que han sido insuficientes para amortiguar el impacto de estos TLC, se puede percibir que el excedente del consumidor de la industria automotriz se está incrementando, debido a la inclusión de nuevas marcas y referencias de automóviles, con precios de venta por debajo o igual es a los producidos en el territorio nacional.

La puesta en marcha del tratado de libre comercio con Corea del Sur y la reducción arancelaria de un $35 \%$ que actualmente se grava sobre los vehículos provenientes de este país y del cero arancel con respecto a los vehículos provenientes de México, se ve reflejada notoriamente en la curva de demanda de esta industria a nivel nacional.

Con esta información se puede inferir con certeza que el comportamiento que presenta la curva de demanda del sector automotriz, en términos de elasticidad, es que dicha demanda vista desde el punto de vista del precio pagado por los consumidores, es elástica. Con la 
introducción de nuevos modelos y marcas que se ajustan a las preferencias de los clientes, en especial por los precios de venta con que son lanzados al mercado, una gran proporción de la población abarcará este segmento de mercado, con precios más bajos que los ofrecidos por la producción nacional. (Ver Figura 3).

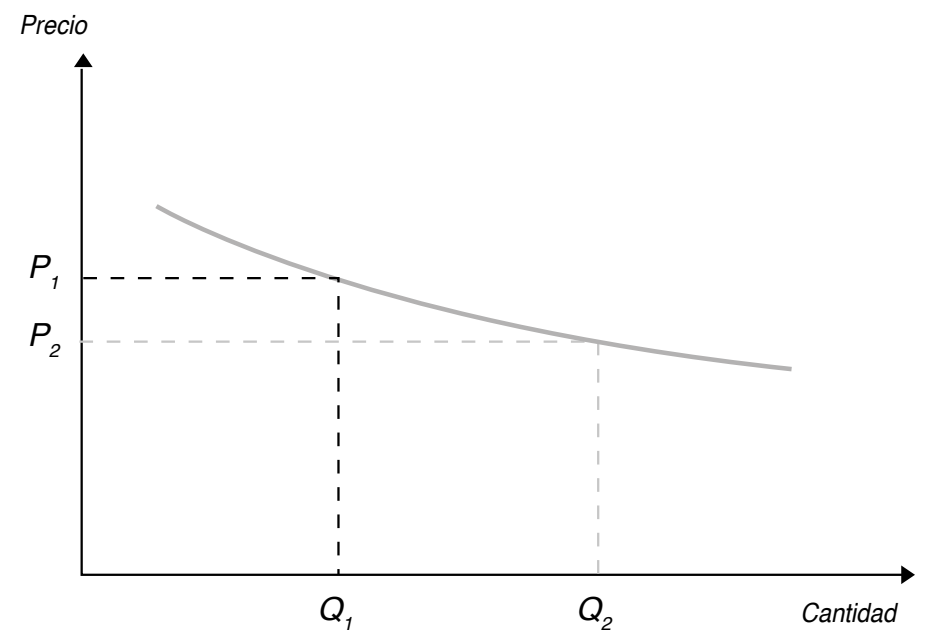

Figura 3. Aproximación gráfica del comportamiento de la curva de demanda de la industria automotriz en Colombia frente a su situación actual y la intervención del Estado.

Fuente: Elaboración propia

Este comportamiento elástico de la demanda es el resultado de las observaciones realizadas por el Departamento Administrativo Nacional de Estadística (DANE) y la Asociación Nacional de Empresarios (ANDI), las cuales fueron compiladas por estos dos organismos de acuerdo con las preferencias de los consumidores con respecto a tipo de vehículo, marca, precio, créditos para adquisición de vehículos, destino (privado o público), entre otras, dando como resultado que la demanda de vehículos en Colombia tenga un comportamiento similar al que presenta la Figura 3.

Asimismo, la entrada de nuevos vehículos, de marcas reconocidas y nuevas para el país a precios bajos y de fácil acceso, no solo está ocasionando problemas económicos, sino también internos. Las metrópolis sufren con los extensos trancones provocados por una gran cantidad de vehículos que fluyen en las escasas vías en las llamadas "horas pico". Para ello, el intervencionismo realizado por el Estado para contrarrestar este fenómeno ha sido la creación del "pico y placa” el cual consiste en que a determinadas horas, en las vías de las principales ciudades, sólo transiten vehículos que terminen con un número específico en la matrícula o placa, para un día determinado. Esto a su vez contribuye a la descongestión vehicular y la contaminación ambiental.

Este comportamiento elástico de la demanda es el resultado de las observaciones realizadas por el Departamento Administrativo Nacional de Estadística (DANE) y la 
Asociación Nacional de Empresarios (ANDI), las cuales fueron compiladas por estos dos organismos de acuerdo con las preferencias de los consumidores con respecto a tipo de vehículo, marca, precio, créditos para adquisición de vehículos, destino (privado o público), entre otras, dando como resultado que la demanda de vehículos en Colombia tenga un comportamiento similar al que presenta la Figura 3.

Asimismo, la entrada de nuevos vehículos, de marcas reconocidas y nuevas para el país a precios bajos y de fácil acceso, no solo está ocasionando problemas económicos, sino también internos. Las metrópolis sufren con los extensos trancones provocados por una gran cantidad de vehículos que fluyen en las escasas vías en las llamadas "horas pico". Para ello, el intervencionismo realizado por el Estado para contrarrestar este fenómeno ha sido la creación del "pico y placa" el cual consiste en que a determinadas horas, en las vías de las principales ciudades, sólo transiten vehículos que terminen con un número específico en la matrícula o placa, para un día determinado. Esto a su vez contribuye a la descongestión vehicular y la contaminación ambiental.

De igual manera, el Estado, por medio de los Departamentos de Tránsito y Transporte ha retrasado el otorgamiento de licencias a los conductores. Pero estas medidas se quedan escasas al considerar el volumen de vehículos que se venden en el país. Sin embargo, el Estado colombiano al considerar que sus políticas no han tenido ningún tipo de resultados positivos, sólo se refugia en que la única manera de rescatar la industria automotriz es con la innovación y el desarrollo de nuevos prototipos, que sean más competitivos tanto en el mercado nacional como en el extranjero.

\subsection{El excedente del productor y la elasticidad de la oferta}

Ahora bien, si se mira la situación actual de la industria automotriz en Colombia, el excedente del productor se está viendo afectado negativamente, debido a que la industria nacional está siendo obligada a competir con productos que son importados al territorio nacional a precios más bajos que los producidos localmente.

De esta manera, los consumidores tendrán mucho más variedades de vehículos para escoger, producto de la excesiva oferta, poniendo en riesgo el funcionamiento de las ensambladoras nacionales los cuales deberán disminuir sus precios de venta y al mismo tiempo ofrecer mejores prototipos con costos de producción más bajos, colocando en la balanza la calidad de los productos y la seguridad de los usuarios.

Con respecto a la elasticidad de la oferta, la situación económica por la cual está pasando el país con la apertura a nuevos mercados por medio de tratados de libre comercio ha transformado la curva de oferta, haciéndola más elástica debido a la inclusión de nuevas marcas y modelos de vehículos y la alta competencia que se ha generado entre la industria nacional y la extranjera.

De esta manera, la curva de la oferta de la industria automotriz puede que se encuentre representada como se presenta en la Figura 4. 


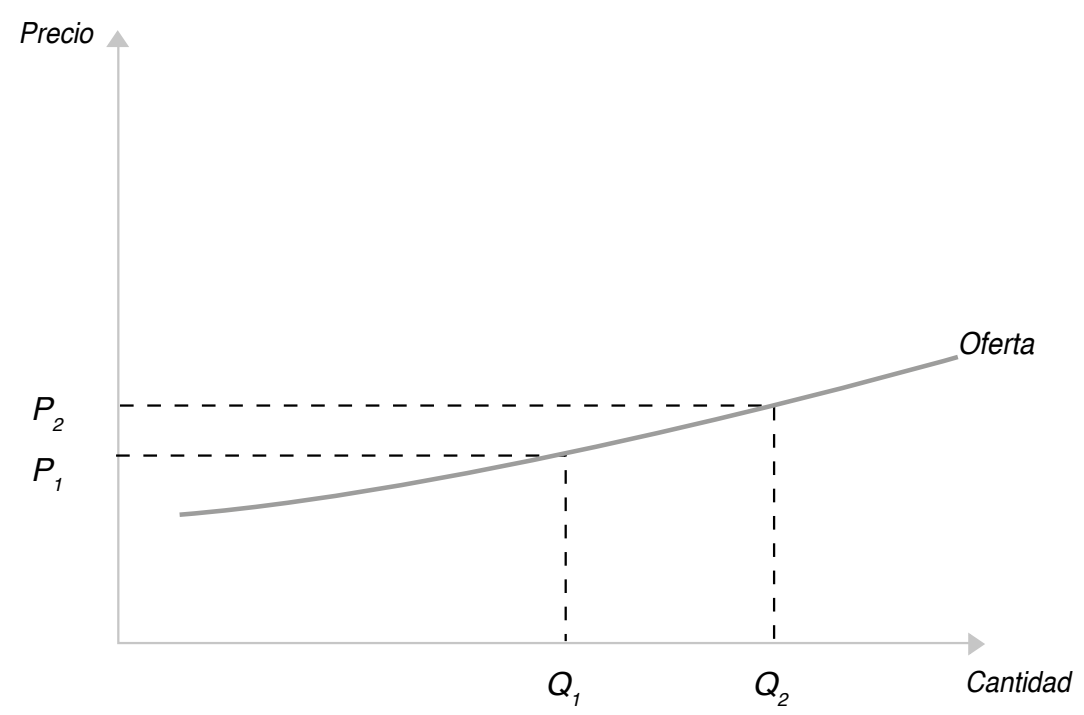

Figura 4. Aproximación gráfica del comportamiento de la curva de oferta de la industria automotriz en Colombia, frente a su situación actual y la intervención del Estado.

Fuente: Elaboración propia.

\subsection{Análisis de la eficacia de la intervención estatal}

En relación con la intervención del Estado en la industria automotriz, esta no ha sido eficaz a la hora de mitigar los efectos adversos a los productores, causados principalmente por los tratados de libre comercio. La creación del PIPE y el PROFIA, a través de créditos otorgados por Bancoldex para el gobierno nacional y que de ahí este se pueda inyectar a las empresas nacionales de ensamblaje y fabricación de autopartes no fue suficiente para salvaguardar la economía nacional en este sector.

En el año 2013, el gobierno aprobó tales políticas sin resultados positivos. En el 2014 nuevamente el Estado colombiano se pronuncia aclarando simplemente que para que la industria automotriz tenga éxito para competir en el mercado nacional y en el internacional, debe invertir en desarrollo tecnológico e innovación.

Las decisiones del gobierno nacional colombiano de abrir el mercado automotriz a la competencia extranjera han traído perjuicio a los productores nacionales y ha perjudicado el empleo en el sector. La otra cara de la moneda son los centenares de miles de consumidores que se benefician de poder acceder a un vehículo en mejores condiciones renovando con esto su calidad de vida. En política económica debería primar el interés de las mayorías, sin embargo, también compensar y ayudar a quienes pierden con estas decisiones.

El Estado debería permitir una mayor competencia en aras de alcanzar niveles óptimos de eficiencia productiva en el sector y que los beneficios de estas mejoras en la eficiencia 
sean trasladadas al consumidor final. De igual modo, continuar con las políticas de apoyar a la industria nacional en su proceso de reconversión y de ayudar a quienes se queden sin empleo a su reincorporación en otras áreas.

Por parte de la industria automotriz colombiana conviene redoblar esfuerzos, hacer las inversiones y cambios necesarios a fin de avanzar hacia estándares de competitividad a escala mundial, único camino sostenible de posicionamiento en el mercado en el largo plazo, a fin de no requerir la protección estatal para sobrevivir ante empresas internacionales más competitivas. La protección estatal sólo debe ser una medida transitoria.

Se piensa que es posible, a largo plazo, una política económica donde todos ganen, tanto productores, como empleados, como consumidores, esto es equidad. Si se piensa en el bienestar de todos, podremos tener políticas económicas para beneficio de todos. La economía no es necesariamente un juego de poder de ganadores y perdedores, también es posible una política económica de cooperación, donde todos ganen, esto es equidad.

\section{Conclusiones}

La industria automotriz y de autopartes, venía presentando un incremento muy positivo desde el 2007, aportando al PIB industrial cerca de 5,6\% y con una alta aceptación en el mercado nacional. Desde que en los años 2011 y 2012 se pusieron en marcha los tratados de libre comercio, el panorama de esta industria sufrió un duro golpe por la inclusión de nuevas marcas y nuevas tecnologías al territorio nacional, capaces de cumplir con las expectativas de los consumidores, muy por encima de las características ofrecidas por la producción nacional.

Sin duda alguna, la piedra angular que generó este comportamiento tanto de la oferta como de la demanda, fue la firma de tratados comerciales con otros países que, hoy por hoy, están posicionados como potencias en la fabricación de vehículos y autopartes, tales como México y Corea del Sur.

A raíz de esto, el gobierno implementó políticas proteccionistas, con la fijación de impuestos a ciertas partidas arancelarias, con el fin de proteger la industria nacional, asimismo, la consecución del Estado colombiano de un capital de trabajo por medio de Bancoldex para impulsar esta industria y otorgar créditos a largo plazo con cupos hasta de 50 mil millones de pesos. Estas medidas no fueron lo suficientemente capaces de salvaguardar los efectos negativos producto de las relaciones comerciales entre los países que tienen TLC con Colombia.

Ciertamente, los más afectados son los productores, ya que deben encontrar la mejor manera de optimizar sus costos con el fin de ofrecer productos que compitan directamente con la industria extranjera, y mucho más cuando ya se tiene un gran segmento de la población pagando precios más bajos por los vehículos importados, muy por debajo de los costos locales. 
Sin embargo, cabe resaltar que se debe tener en cuenta que la innovación juega un papel importante y el Estado n sólo debe comprometerse a amplificar la infraestructura de las ensambladoras, sino también apoyar el diseño e innovación en toda la cadena productiva de la industria automotriz nacional, con el propósito de reducir los costos de fabricación y hacer que los precios nacionales compitan directamente con los internacionales.

\section{Conflicto de intereses}

Los autores declaran no tener ningún conflicto de intereses.

\section{Referencias bibliográficas}

1. Asociación Nacional de Empresarios (ANDI) 2014. La industria automotriz en Colombia. Cámara Automotriz ANDI. Recuperado agosto 8 de 2016. Disponible en: http://www.andi.com.co/pages/comun/infogeneral.aspx?Id=76\&Tipo=2

2. BBVA (2013). Situación automotriz Colombia 2013. Recuperado el 10 de julio de 2016. Disponible en: https:/www.bbvaresearch.com/wp-content/uploads/ migrados/140410_Situaci_nAutomotriz_Colombia2013_tcm346-444417.pdf

3. Corficolombiana (2012). Perspectivas económicas de Corficolombiana proyecciones 2012: Bancos centrales al rescate. Investigaciones económicas Corficolombiana. Recuperado agosto 15 de 2016. Disponible en:http://www.corficolombiana.com/ webcorficolombiana/Repositorio/archivos/archivo1295.pdf

4. Departamento Administrativo Nacional de Estadística - DANE (2014). Muestra Mensual Manufacturera. Balance 2012-2014. Recuperado el 26 de agosto de 2016. Disponible en: http://www.dane.gov.co/index.php/industria/muestra-mensual-manufacturerammm/112-boletines/industria/2768-muestra-mensual-manufacturera-mmm

5. Ministerio de Comercio, Industria y Turismo. (17 de Diciembre de 2013). Decreto 2910 de 2013. Recuperado agosto 25 de 2016. Disponible en: http://www.mincit.gov.co/ documentos.php?id=323.

6. Revista Dinero. (2014). Crisis en el sector automotriz no encuentra solución. Bogotá D.C.: Revista Dinero. Recuperado agosto 27 de 2016. Disponible en: http://www.dinero. com/empresas/articulo/industria-automotriz/194131

7. Revista Sectorial (2014). Informe sector automotriz colombiano. Grupo Inercia valor. Recuperado agosto 20 de 2016. Disponible en: https://www.sectorial.co/index. php?option=com_k2\&view=item\&layout=item\&id=75\&Itemid=220

8. Pindyck, R., \& Rubinfeld, D. (2009). Microeconomía. 8ª . Edición. Págs. 55-59. Madrid. Pearson Prentice Hall. 